\title{
Estar, e não ser, aliado: A sociabilidade dos índios do Chaco durante o avanço colonial no século XVIII
}

Guilherme Galhegos Felippe*

Resumo: Quando missionários e funcionários do Estado espanhol foram instruídos pela Coroa a explorar e colonizar a região do Chaco para formar um caminho direto entre o porto de Buenos Aires e as minas andinas, o contato com os nativos foi, segundo o que se pode evidenciar na documentação produzida, a maior dificuldade enfrentada pelos espanhóis que tentaram se estabelecer naquela região. Uma das principais reclamações de missionários e colonos girava em torno da falta de comprometimento que os índios mantinham frente a contratos ou a alianças para, por exemplo, o estabelecimento de reduções catequéticas. A colaboração que os índios prestavam, num primeiro momento, logo transformava-se em traição, aos olhos dos espanhóis, quando os nativos abandonavam as reduções ou envolviam-se em comercializações ilícitas com os portugueses. Este modo de agir dos chaquenhos foi identificada como uma conduta inconstante e reprovável pelos colonizadores, que buscaram diversas formas de revertê-la. O presente artigo tem como objetivo demonstrar que esta inconstância, na verdade, era um aspecto fundamental do sistema sociológico nativo, em que estabelecer alianças ou inimizades era a forma de dinamizar a sociabilidade dos grupos chaquenhos e, com isso, manter sua integridade.

Palavras-chave: Índios do Chaco. Inconstância indígena. Alianças e inimizades. Século XVIII.

* Pós-Doutorando em História, PUCRS. Contato: guilhermegfelippe@gmail.com. 
Estar, e não ser, aliado: A sociabilidade dos índios do Chaco...

\section{Introdução: a inconstância indígena}

O padre Pedro Lozano conta que os Guaicuru que estavam assentados no rio Paraguai, à margem oposta à cidade de Assunção, mantinham uma convivência pacífica com os citadinos - ou, pelo menos, de não agressão. Porém, ao final do ano de 1677, os assuncenhos notaram que os índios se mostravam mais hostis, já que os que frequentavam a cidade (LOZANO, 1733, fl. 60-62) "[...] venían armados con cuantos géneros de armas podían cargar, cosa que también causaba extraña novedad". A situação deixou os moradores da cidade em alerta, desconfiados de que os Guaicuru planejassem assaltá-la. Descobriu-se, por fim, que em poucos dias os índios invadiriam a cidade, fazendo com que o Governador da Província, junto com o bispo de Assunção, tramassem uma emboscada: fingiram o interesse em estabelecer uma aliança com os índios através do casamento entre o Tenente Geral da cidade, Don José de Avalos, e a filha de um dos caciques principais. O Tenente, inclusive, "para mayor disimulo", foi pedir a mão da índia vestido "[...] a la moda de los Guaycurús, andando como ellos con su arco y flechas cubierto sólo de plumas" (LOZANO, 1733, fl. 60-62). Após o pedido ser aceito e a data do casório ser marcada para o dia vinte de janeiro de 1678, os preparativos para o festejo foram organizados pelos espanhóis de tal forma que todos os convidados indígenas ficariam juntos em três casas, nas quais estariam ocultos "[...] soldados armados en buen número que diesen sobre los convidados" (LOZANO, 1733, fl. 60-62), bem como uma tropa de cavalaria e uma de infantaria atacariam, no mesmo instante, os demais índios assentados às margens do rio Paraguai.

O plano só não ocorreu perfeitamente porque os Guaicuru, desconfiados, mantiveram-se precavidos frente a toda situação, mantendo alguns índios escondidos espionando os movimentos dos colonos. Os Guaicuru, "[...] tan versados en traiciones [...]", descobriram a trama pretendida pelos espanhóis no dia que havia sido marcada a festa, provocando então o embate entre os dois grupos. Como a maior parte dos índios já estava na cidade, a refrega foi favorável aos assuncenhos, que deram baixa de cerca de trezentos nativos e obtiveram o resultado que pretendiam: o afastamento dos

Anos 90, Porto Alegre, v. 22, n. 41, p. 267-298, jul. 2015 
índios. Porém, como finaliza o autor do caso, “[...] desde entonces ha quedado toda esta nación con más odio contra los españoles con quien después acá nunca han renovado la paz y mantienen la guerra con todo empeño" (LOZANO, 1733, 』 IX, fl. 60-62).

O relato do padre Lozano tem a importância não somente de fornecer um exemplo da complexa situação em que estavam envolvidos os índios e os moradores das cidades, mas também por expressar uma situação que me parece fundamental para a discussão proposta: a brusca mudança da condição dos índios na sua relação com os colonos, passando de possíveis invasores a potenciais parentes. O que parece ter acontecido é que o Governador, percebendo os índios como oscilantes em suas relações, articulou uma emboscada cujo fundamento era utilizar esta falta de perseverança indígena contra eles mesmos: partia da ideia de que, mesmo intencionados a invadir a cidade, aceitariam facilmente o estabelecimento de uma união parental - como se as relações indígenas fossem todas tão superficiais como efêmeras. O Governador articulou uma emboscada baseando-se na imagem que se construiu acerca dos índios ao longo das décadas de contato, na qual os nativos eram inconstantes em suas relações e, acima de tudo, não confiáveis.

Esta inconstância foi uma das adjetivações mais frequentemente usadas pelos autores que conheceram e conviveram com os índios da América meridional, fundou um perfil pejorativo sobre a conduta e, inclusive, o caráter dos nativos. Sem entender por que os índios eram tão voláteis e aparentemente desapegados a praticamente tudo o que lhes ensinassem, os observadores hispanófonos acusaram um crônico déficit cognitivo e inaptidão à conduta civilizada - situação que só seria contornada, acreditava-se, com o persistente ensino cristão, por meio da tutela missionária:

[...] si han de emplear su celo entre gente la más pobre y desfavorecida de la fortuna por su innata desidia y sobre esto inconstante, vagabundo y no acostumbrada al trabajo, gente bárbara en todas sus costumbres, es necesario que el exordio y progreso de este apostolado americano le formen y acompañen otras bien distintas e inopinadas fatigas (MONTENEGRO [15/08/1745], fl. 12).

Anos 90, Porto Alegre, v. 22, n. 41, p. 267-298, jul. 2015 
Estar, e não ser, aliado: A sociabilidade dos índios do Chaco...

O que pretendo demonstrar aqui é que a inconstância indígena descrita pelos observadores dizia menos sobre a conduta nativa do que como os índios entendiam o Outro, tendo em vista que estas atitudes eram impressões do observador branco em relação a atitudes que lhes pareciam ilógicas e inconvenientes. Isso explica, por exemplo, por que missionários e autoridades civis discordavam a respeito da origem dessa inconstância indígena. Para o jesuíta José Francisco de Arce, essas atitudes eram provocadas pelos colonos que faziam com que os índios tornassem-se arredios ao contato. Num contexto de reafirmação do jesuitismo frente aos conflitos com os colonos, o discurso do missionário apoia-se na história do contato repleta de abusos cometidos pelos espanhóis contra os índios. O missionário exemplifica, relatando um caso em que os índios Payaguá, depois de terem sido atendidos em sua solicitação para serem reduzidos pelos padres da Companhia de Jesus, são atacados por espanhóis que se aproveitaram "[...] que se habían juntando muchos de dichos indios con sus canoas en la playa del río” (ARCE [23/07/1707], fl. 2). Já o padre Angelo Petragrassa ([22/07/1707], fl. 1v) alertava que os chaquenhos também eram hostis com os missionários, devido aos maus tratos que sofriam dos colonos, dificultando a conversão.

Culpavam-se, assim, os costumes viciosos dos hispano-crioulos pelos fracassos que se seguiam nas tentativas de contato, conversão e redução dos índios do Chaco, principalmente porque as relações estabelecidas entre os colonos e os chaquenhos foram praticamente sempre pautados pela violência de ambas as partes, o que distanciava as possibilidades de se implantar um projeto de conversão. Porém, a inconstância dos índios do Chaco não se manifestava apenas para os missionários: há quase uma unanimidade nos discursos administrativos do século XVIII sobre a dificuldade em manter uma relação estável e sem sobressaltos com os nativos. A formação e manutenção de acordos comerciais ou bélicos era um importante instrumento político para os espanhóis, que não entendiam a indisciplina indígena e a instabilidade nas relações que estabeleciam. Dessa forma, aos observadores, os chaquenhos pareciam "ignorantes de toda la ley de la razón” (CABILDO DE ASSUNÇÃO [30/05/1763], fl. 2v). Criou-se a imagem de que os índios eram traidores e interesseiros, de difícil trato, devido à sua inconstância no modo de agir: se, num 
primeiro momento, davam toda a certeza de uma aceitação irrestrita e completa, em seguida, já apresentavam total descaso e descompromisso. Viveiros de Castro (2002, cap. 3), em seu importante artigo sobre a inconstância dos Tupinambá, constatou que os índios no Brasil colonial não rechaçavam as novas ideias ou as pregações que os missionários lhes instruíam, aceitando-as de imediato e sem questionamentos, mas desinteressando-se por completo logo em seguida: "[...] a aceitação entusiástica mas altamente seletiva de um discurso totalizante e exclusivo, a recusa em seguir até o fim o curso desse discurso, não podiam deixar de parecer enigmáticos a homens de missão" (id. ibid., p. 191).

No Chaco, não parecia ser diferente. O jesuíta José Sánchez Labrador responsabiliza os próprios Mbayá pelo fracasso da redução Nuestra Señora de Belén, pois "[...] de una hora para otra se ve deshecho lo que parecía más bien fundamento contra los vaivenes de sus genios inconstantes" (1770, t. 1, p. 252). Esta conduta volátil também era observada nos Mataguayo, que solicitavam reduções e até se mudavam para elas, mas "[...] sin motivo alguno las han desamparado, huyendo a sus antiguas guaridas" (BUENO [1775], fl. 5). O Governador do Rio da Prata, durante as primeiras negociações com os Abipone para o estabelecimento de uma redução, alerta que "[...] no se puede afianzar constancia de sus genios y poca estabilidad para permanecer en ella, lo que precisa a vivir con el cuidado conveniente para evitar cualquiera estrago repentino [...]", aconselhando, assim, o envio de "[...] 500 Dragones de refuerzo para el aumento de esta plaza por ser indispensable y preciso haya en ella mil hombres para ocurrir a la asistencia de guardias y guarniciones" (SALCEDO [20/07/1734], fl. 1-2).

Este sempre voltar atrás que os índios realizavam nos acordos ou tratos com os espanhóis resultou numa imagem quase estanque não só dos nativos como também de seu comportamento, que acabou sendo vinculada a discurso edificante dos missionários. A paciência e o esforço prestado pelos padres justificavam-se como os principais instrumentos para se alcançar resultados eficientes na conversão e civilização de índios tão instáveis. Daí a relação que o padre Alonso Sánchez fez desta tarefa apostólica com o trabalho manual:

Anos 90, Porto Alegre, v. 22, n. 41, p. 267-298, jul. 2015 
Estar, e não ser, aliado: A sociabilidade dos índios do Chaco...

En una palabra es menester haberse con ellos como el escultor con un tosco leño, que primero emplea el hacha para desbastar y después el escoplo y otros instrumentos más sutiles para formar y perfeccionar las facciones de una estatua. Así es forzoso enseñarles primero a vivir como hombres, para que después aprendan a vivir como cristianos. O como quien quiere amansar fieras bravas, que sólo a fuerza de mucha paciencia y de apacentarlas bien, lo consigue (PADRE ALONSO SÁNCHEZ apud FURLONG, 1939, p. 63).

A relação entre o trabalho missionário de catequese e a conversão das almas indígenas parece ter sido frequentemente comparada ao árduo trabalho manual, já que, para além dos ensinamentos espirituais e dogmáticos, era um ofício que demandava paciência e habilidades técnicas para o convívio com os nativos, que requeriam muitos esforços práticos dos missionários. Daí a alegoria do mármore e da murta que o padre Antonio Vieira havia feito, em meados do século XVII, em relação aos Tupinambá da costa brasileira (VIVEIROS DE CASTRO, 2002, cap. 3). No final do século XVIII, motivados pela dificuldade em estabelecer uma relação com os índios, estas comparações ainda eram realizadas pelos missionários, como fez o padre Martín Dobrizhoffer:

Deducirás seguramente que transformar a estos bárbaros en cristianos fue trabajo más lento y de mayor arte que modelar una estatua de Mercurio de una estaca y no te admirarás en absoluto de que a tan grandes esfuerzos de nuestros hombres hayan respondido frutos tan pequeños, los cuales no obstante no deben despreciarse si se sopesa la dificultad de la obra $\left(1784\right.$, t. 3, p. 351). ${ }^{1}$

A inconstância indígena foi incorporada como o discurso do colonizador que antecipava o trato com os nativos: definia-se o comportamento volátil dos índios como sendo a origem de todos os problemas enfrentados não só pelos missionários como pelos colonos em geral, tanto na questão da conversão e do trabalho apostólico como nos tratos cotidianos que iam desde as relações comerciais até a convivência nas cidades. Segundo Viveiros de Castro, ainda 
em sua análise sobre os Tupinambá da costa do Brasil colonial, a inconstância dos índios derivava da ausência da centralização de poderes tanto políticos como religiosos aos quais os nativos deveriam obedecer, sob o risco de infrações sociais. Assim, a religião dos Tupinambá, por mais contraditória que pudesse parecer, não se baseava em um conjunto de crenças e, por isso, não tinha como fundamento a prática pela obediência ou coerção:

Os selvagens não crêem em nada porque não adoram nada. E não adoram nada, no fim das contas, porque obedecem a ninguém. A ausência de poder centralizado não dificultava apenas logisticamente a conversão [...]; ela a dificultava, acima de tudo, logicamente (VIVEIROS DE CASTRO, 2002, p. 216-217).

Os observadores setecentistas também notaram que os chaquenhos não prestavam cultos a divindades superiores. $O$ padre Pedro Lozano, por exemplo, afirma que os índios do Chaco não "[...] reconocen deidad alguna a quien rindan culto o adoración [...]", preocupando-se apenas em "[...] gozar de una perniciosa libertad nacida de una voluntad sin rastro de sujeción, ni a Dios, ni a los hombres" (LOZANO, 1733, 』XVI, fl. 96).

Em relação aos seus caciques, não era diferente: o trato que os índios possuíam com suas lideranças não estava pautado pela incondicional obediência ou uso de qualquer tipo de coerção. As relações seriam, portanto, vazias de mando e sujeição, fazendo com que os índios não conhecessem "[...] más sumisión que su absoluta voluntad” (ROZAS, [29/10/1744], fl. 1v).

O problema visualizado pelos espanhóis foi que os índios, apesar de parecerem reconhecer uma liderança entre os membros do grupo, não despendiam a esta pessoa mais deveres que a qualquer outro membro - inclusive podendo deixar de segui-la como líder a qualquer momento:

Generalmente no tienen gobierno alguno civil, ni observan vida política: solo en cada tierra ay un Cacique, á quien tienen algún respecto, y reverencia, que sólo dura mientras se les da alguna ocasión de disgusto, por el cual fácilmente se separan (LOZANO, 1733, § VII, fl. 55).

Anos 90, Porto Alegre, v. 22, n. 41, p. 267-298, jul. 2015 
Estar, e não ser, aliado: A sociabilidade dos índios do Chaco...

Isto acabava se refletindo no ambiente reducional, em que os índios, como em suas aldeias, não obedeciam a tudo o que lhes mandavam. Assim, a disciplina dos Abipone, mesmo após décadas de experiência missionária, foi alvo de crítica dos funcionários coloniais, que concluíram que os " [...] doctrineros no tienen fuerzas para castigarlos, ni para sujetarlos, porque no los obedecen: se van cuando se les antoja y vuelven cuando quieren" (AUTOS, [02/09/1775], fl. 1v). Florián Paucke alerta que os missionários não deveriam usar de "una voz demasiado alto" com os índios, sob o risco de acreditarem que o padre "[...] quiere obligarlos a la fuerza y está enojado con ellos" (1767, t. 2, p. 57). A ausência de uma centralização política ou expedientes que vinculassem sujeitos a um cargo de mando ou administração social dificultava a lógica da relação sociopolítica imposta dentro das reduções, resultando que os índios não se subjugavam nem aos padres, nem aos demais neófitos: "Ni aún en la reducción hacían caso del corregidor, ni le obedecían" (ANDREU, [22/11/1757], fl. 26).

A atitude indígena de tomar as suas próprias decisões, obedecendo as suas vontades e necessidades, sem pautá-las por procedimentos relacionais que precederiam a relação em si, não era uma conduta opcionalmente canalizada para o contato com os brancos: os índios agiam com os espanhóis como agiam entre si, fazendo desta inconstância - seja qual o for o nome dado a este proceder indígena um traço da sua sociabilidade. Assim, os índios podiam ignorar ou se interessar por tudo o que lhes conviesse, e, de qualquer forma, estariam emitindo algum tipo de relação social. Mas, frente a todas as inconstâncias e instabilidades que podiam apresentar em suas relações e estabelecimento de acordos, os grupos chaquenhos estavam longe de se dispersarem em unidades nucleares autônomas umas das outras.

Dito de outra forma, a inexistência de uma obediência político-hierárquica dentro do grupo não resultava numa consequente fragmentação tribal que provocaria o desmantelamento das aldeias enquanto unidade. Sem estarem às margens do estabelecimento de um Estado mediador e tutelar das relações sociais e políticas, nem do perigo de extinção, devido a um estiramento das instáveis relações intrapessoais, os grupos chaquenhos possuíam mecanismos e expedientes sociológicos que, ao mesmo tempo em que movimentavam centrifugamente os índios para o estabelecimento de relações com o

Anos 90, Porto Alegre, v. 22, n. 41, p. 267-298, jul. 2015 
estranho, forçavam a internalização de bens simbólicos e materiais por meio da sociabilidade tribal. Eram essas relações cotidianas, galvanizadas pelos elementos externos, que davam razão ao grupo enquanto tal, possibilitando sua atualização, reprodução e integração.

\section{A guerra como geradora de sociabilidade}

Ora, se a quase unanimidade das descrições que são feitas sobre as relações que os nativos cultivavam se direciona para uma oscilação aparentemente desregrada entre a cooperação amistosa e a hostilidade, talvez devam-se questionar os conceitos de aliança e inimizade na compreensão indígena. Ao entendermos que, segundo os relatos, a inconstância era a frequência com que os nativos voltavam atrás e rompiam alianças ou acordos estabelecidos tanto com outros índios como com não índios, então podemos pontuar que o Outro, para o indígena, prestava um papel muito mais complexo do que o maniqueísmo moral figurativo entre o bom e o mau. As relações indígenas não estavam estabelecidas na rigidez destes dois extremos de oposição, ou, pelo menos, não fixavam neles diretrizes convencionais de sociabilidade - como se as relações de cooperação uma vez estabelecidas entre dois grupos não pudessem ser rompidas sem ver nascer a marca da traição. As alianças, como ressaltou Carina Lucaioli, foram "[...] muy flexibles, esporádicas y limitadas a situaciones específicas [...]”, não havendo "una cooperación sistemática frente a los intentos del dominio español ni alianzas duraderas entre los grupos [...]" (2011, p. 81). Ou seja, a guerra prevalecia sobre a aliança: "[...] é a guerra como instituição que determina a aliança como tática” (CLASTRES, 1980, p. 260). Assim, entre os grupos nativos, o que parecia ocorrer era a atribuição de uma maior importância à relação em si, que se poderia resumir como sendo um estado de afinidade generalizada.

Viveiros de Castro entende a afinidade como o axioma relacional da socialidade amazônica, contrapondo-a à consanguinidade, na medida em que a primeira é a "[...] função do dado na matriz relacional cósmica, ao passo que a consanguinidade irá constituir a província do construído, daquilo que toca à intenção e ação humanas

Anos 90, Porto Alegre, v. 22, n. 41, p. 267-298, jul. 2015 
Estar, e não ser, aliado: A sociabilidade dos índios do Chaco...

atualizar" (2002, p. 406). O que o antropólogo está afirmando é que, se para as sociedades complexas os laços consanguíneos são a marca inquestionável do parentesco cognático, aos grupos tribais das terras baixas sul-americanas, estes devem ser construídos, pois não são dados. Disso decorre o fato de os grupos sul-ameríndios não só permitirem a internalização de pessoas de fora ao grupo cognático, como manterem rituais de afinização de seus próprios membros, numa constante transformação da pessoa em um membro consanguíneo.

Isso também parece ser válido para os grupos chaquenhos setecentistas. Ao mostrarem-se inconstantes em suas atitudes frente aos colonos e mesmo em relação a outros grupos nativos, os índios do Chaco viabilizavam, para si, as possíveis alternativas de relações que estavam em jogo. Se todos eram passíveis de uma relação - e este é o ponto focal -, então a aliança e a inimizade eram os coadjuvantes em uma peça cujo cenário era o ator principal: a afinidade era a base que suportava as correlações. Sendo assim, ser aliado ou inimigo era uma situação, e não uma condição - era o estar antes do ser. A inconstância dos chaquenhos era, portanto, uma via de possibilidade relacional: quanto maior a oportunidade de estabelecer relações sociais - fossem de aliança, fossem de inimizade -, maior as chances de conformar a coesão tribal. Daí a constatação dos observadores hispanófonos sobre um dos poucos momentos em que os índios se mostravam unânimes: a guerra.

O vice-rei do Peru, em carta ao Rei da Espanha, afirma que, apesar de os índios não terem "entre ellos cacique dominante", unem-se para "[...] hacer la guerra al español o a otras naciones sus enemigas” (CONDE DE SUPERUNDA, [15/02/1751], p. 17-18). Florián Paucke, missionário entre os Mocovi, afirma que os “[...] indios obedecen a su cacique cuando ellos quieren [...]", exceto quando este "los invita a cometer un robo o a pelear contra otros o invadir las estancias españolas y matar los habitantes, entonces todos corren junto a él" (1767, t. 2, p. 104-105, grifos no original). Os espanhóis constataram que a união do grupo girava em torno de uma mesma causa e, não necessariamente, de um líder:

Lo que únicamente puede decirse es que un consentimiento tácito los une y coliga para mirar por su conservación y

Anos 90, Porto Alegre, v. 22, n. 41, p. 267-298, jul. 2015 
mutuamente no destruirse. En fuerza del mismo, toman las armas arbitrariamente y se ayudan a hacer a otros la guerra, si conciben, o que volverán con un rico botín de despojos, y cautivos, o que así conviene para rebatir la fuerza de su enemigo (SÁNCHEZ LABRADOR, 1770, t. 1, p. 306).

A guerra, como já haviam constatado os espanhóis desde os primeiros contatos com os sul-ameríndios, era uma das práticas mais constantes nas quais eles se engajavam. Ainda que a guerra indígena não fosse praticada por um exército formal, organizada a partir de patentes hierarquicamente dispostas, os índios obedeciam a uma lógica em suas incursões que se baseava, fundamentalmente, na cooperação de aliados que extrapolavam o grupo familiar: daí a importância de se manter a sociabilidade através de cerimônias ou práticas comunitárias, como a reciprocidade de dádivas ou os convites festivos. Fazer parte de uma aliança implicava a responsabilidade de manter uma constante prática social com os grupos amistosos, caso contrário, a relação enfraqueceria, podendo converter-se em hostilidade. Por isso, mesmo reduzidos, os índios mantinham contato com grupos não reduzidos - e o próprio espaço reducional era apropriado para a formação de novas alianças. Além de possibilitarem aos índios a continuidade de suas guerras, as reduções acabaram fomentando-as.

Se comparadas com as missões realizadas nos rios Uruguai e Paraná de índios Guarani, as missões chaquenhas não oportunizaram resultados tão significativos ou duradouros. Nas últimas décadas do século XVII, coincidindo com a conquista do Vale de Calchaqui, a região do Chaco passou a ser um importante alvo das missões religiosas empreendidas, principalmente, por jesuítas. Resumiam-se a missões itinerantes que tentavam alcançar o maior número possível de aldeias e toldos indígenas da região (BRUNO, 1968, p. 289-290). No início do século XVIII, as investidas no Chaco tornaram-se mais enérgicas, principalmente com as entradas ofensivas que o Governador Esteban de Urízar y Arespacochaga empreendeu durante o seu mandato, que se estendeu de 1708 a 1724, ano de sua morte. Com o intuito de pacificar os índios por meio da força, o Governador também objetivava atrair os nativos para a vida civilizada, ajudando a fundar pelo menos duas reduções que se mostraram, por um tempo,

Anos 90, Porto Alegre, v. 22, n. 41, p. 267-298, jul. 2015 
Estar, e não ser, aliado: A sociabilidade dos índios do Chaco...

consistentes: San Juan Batista de Balbuena, erguida em 1711, e San Esteban de Miraflores, consolidada em 1714, ambas de índios Lule e sob os cuidados dos jesuítas (VITAR, 2000, p. 8-9). Mas, já em 1725, no relatório de visita do padre Juan Patricio Fernández, constatou-se que os índios reduzidos em Miraflores haviam fugido para suas antigas moradas (1726, v. 2, p. 387). Desde esse período, já se podia notar as grandes dificuldades que obstaculizavam a empresa reducional, em especial a falta de comprometimento dos índios com as coisas da fé, como constatou o Bispo de Córdoba em seu relatório ao Rei sobre as visitas às reduções da Província de Tucumã: "Muchachos y viejos aun no saben bien hacer la señal de la cruz y persignarse: los más no pasan de las cuatro primeras oraciones, raros saben los preceptos de Dios y de la Iglesia y sacramentos de ella" (BISPO DE CÓRDOBA, [20/04/1729], fl. 2).

A partir da década de 1730, as missões chaquenhas intensificaram-se sob a forma de reduções: até o final do século, fundaram-se inúmeras delas com o objetivo de dinamizar a pacificação dos índios - algumas, inclusive, sendo erguidas no interior do Chaco. Mesmo assim, os resultados em relação à conversão dos índios ainda mostravam-se ineficazes. Foi o caso, por exemplo, da redução de San José, fundada em 1734, de índios Vilela, que aparentava ser promissora no seu início. Porém, já em 1757, as notícias sobre os sucessos conquistados em relação à conversão dos índios eram desoladoras. O padre Clemente Jerez, cura da redução, lamentou que "[...] es casi ninguno el adelantamiento espiritual que en ellos se ha logrado, así en la instrucción de la doctrina cristiana y noticia de las obligaciones de nuestra santa ley [...]" (JEREZ, 1757 s. p. apud BRUNO, 1968, p. 491), principalmente por permanecerem em "sus costumbres, abusos y supersticiones gentílicas” (apud BRUNO, 1968, p. 491).

No mesmo ano, o padre Juan Andreu também queixou-se da falta de comprometimento dos Mataguayo que, reduzidos desde o ano de 1750 (VITAR, 1997, p. 294), “[...] nada depusieron de sus brutales costumbres, nada se les pego de la vida racional, nada dejaron de sus supersticiones a que están aferrados con obstinada porfía" (ANDREU, [22/11/1757], fl. 25). Mas, em se tratando dos Mataguayo, essa foi uma reação das menos piores, já que, alguns anos antes, após solicitar reduções, haviam matado os padres Agustín Castañares (MONTENEGRO, 
[15/08/1745]; NUSDORFFER, [30/08/1745], p. 4) e Francisco Ugalde (CA, 1750-1756, p. 11-12; ANDREU, [22/11/1757]), além de, por várias vezes, terem solicitado reduções e fugido das mesmas após seus princípios. Sendo assim, o fato de os Mataguayo não se submeterem à religião e aos ensinamentos dos missionários não era uma atitude inesperada.

Já os Mocovi, mostraram-se mais interessados em fazer parte das reduções. No auge da atuação jesuítica no Chaco, fundaram-se dois povoados exclusivamente mocovis: San Javier, em 1743, e San Pedro, em 1765. Se considerarmos a longevidade da redução de San Javier - que se manteve em funcionamento mesmo após a expulsão da Companhia de Jesus, em 1767, - e o fato de ter sido erguida uma segunda redução para este grupo em 65 , com a finalidade de suprir o continente Mocovi desejoso de juntar-se às missões, chegar-se-ia à conclusão de que os Mocovi foram neófitos mais interessados na conversão. Porém, os registros mostram o contrário. O Tenente da cidade de Santa Fe, alguns meses após a expulsão dos jesuítas, escreveu ao Governador Bucarelli sobre a fuga dos Mocovi da redução de San Pedro: "Tengo por imposible que estos indios se sujeten a reducción, por la suma rebeldía que la experiencia de hechos semejantes ha manifestado en ellos" (MACIEL, 1768, s.p. apud BRUNO, 1970, p. 222). E, mesmo após o estabelecimento de uma terceira redução mocovi - San Francisco Solano de Remolinos -, fundada em 1776 por curas franciscanos, os índios ainda não se resignavam à tutela missionária, muito menos à conversão: “[...] demuestran pocos deseos de abrazar nuestra Fe, porque no hay ninguno bautizado y repugnan se bauticen sus párvulos" (FERNÁNDEZ, [08/06/1779], fl. 2v). O mesmo ocorria aos Mbayá, que, mesmo em redução, não abandonavam "sus prácticas supersticiosas y las bárbaras y perversas costumbres" (JOLIS, 1789, p. 306).

Esse comportamento que os índios mantiveram em relação às reduções pode ser generalizado a todos os grupos que foram abrigados pelas missões religiosas no Chaco: um estar na redução que não significava um estar reduziido. E, para os padres, tal atitude tornava-se mais difícil de compreender, principalmente se levarmos em conta que eram, na maior parte das vezes, os próprios grupos indígenas que vinham solicitar povoados. Esta aparente contradição ganhava destaque entre os missionários, que esperavam atitudes 
Estar, e não ser, aliado: A sociabilidade dos índios do Chaco...

que atestassem a efetiva conversão dos índios que optavam por se juntarem ao espaço reducional. Se os índios não se interessavam pelas coisas da fé e tampouco mostravam qualquer progresso nos ensinamentos catequéticos, o que lhes atraía para dentro das reduções? A resposta imediata que os missionários encontravam para essa pergunta era a inconstância dos índios: sem saberem ao certo o que queriam, movidos principalmente pelos seus instintos e dados a tudo o que lhes conviesse, sem com isso mostrarem-se afeitos a nada, os chaquenhos também não conseguiam compreender a importância de uma vida cristã - daí seu desinteresse em relação às práticas catequéticas. Já as autoridades civis, com outra mirada sobre a situação, tinham respostas mais práticas:

Por cuanto después de los repetidos tratados de paces y treguas que ha habido con las naciones bárbaras Toba y Mocovi, y sus confederados, se han experimentado varias hostilidades de su infidelidad y cruel naturaleza, habiéndose justificado ser sus propuestos sólo a fin de contener nuestras armas, por diferir el castigo que de ellas han esperado y merecen por sus traidoras operaciones, sin que les deba valer la escusa que hasta aquí han tenido de atribuirse unas o otras parcialidades los insultos que se han ejecutado en las fronteras (MONTEROS, [24/04/1745], fl. 1-1v).

O Governador da Província de Tucumã refere-se, no início do trecho, ao acordo de fundação da redução de San Javier de índios Mocovi - que também contava com parcialidades Toba e de grupos aliados. Mesmo sob um acordo de paz e já instalados em uma redução, os índios ainda cometiam suas ações furtivas às cidades e estâncias, levando o Governador a concluir que os nativos só aceitavam estabelecer aproximações amistosas com os espanhóis para continuar suas incursões bélicas. $\mathrm{O}$ autor do trecho não parece estar de todo errado, se levarmos em consideração que os índios, mesmo após ingressar nas reduções, mantinham suas guerras - e não apenas contra espanhóis, como constatou Azara sobre os Mbayá reduzidos desde 1756:

Anos 90, Porto Alegre, v. 22, n. 41, p. 267-298, jul. 2015 
No sólo han hecho guerra a los españoles, y Guaraní, sino también a los Chiquitos, de los cuales hoy tienen más de 150 cautivos, y hace como 15 años que con apariencias pacíficas se llegaron a los Pueblos que los portugueses han fundado uno en cada banda del Rio Paraguay hacia la latitud de $19^{\circ}-30^{\prime}$ y en ellos mataron 125 personas. Desde el año de 1756 en que hicieron la paz con nosotros no la han quebrantado, y sólo hacen la guerra a los pusilánimes Caaguá o Monteses que habitan los bosques vecinos al Rio Xexuy, y alguna vez a los Lengua en el Chaco (AZARA, 1790, p. 374, grifos no original).

Os índios, ao juntarem-se às reduções, não abdicavam de seus tradicionais costumes em função de uma nova perspectiva de vida - no caso, a cristã. Pelo contrário: o que a documentação evidencia é a manutenção de práticas autóctones e, inclusive, a permanência das atuações violentas. O meio reducional proporcionou aos índios vantagens materiais e estratégicas que acrescentavam elementos à dinâmica relacional nativa - ao invés de substituí-la. Pode-se mesmo afirmar que os acordos de aliança e redução potencializaram certos setores da sociabilidade indígena, como constata-se na guerra.

Para além da questão espiritual e catequética, as reduções eram pensadas como espaços de integração geográfica e de delimitação territorial que fundamentavam as fronteiras coloniais - tanto para os limites entre os territórios luso-hispânicos como para as demarcações inter-regionais do próprio território colonial espanhol - como era o caso das reduções que demarcavam os limites do Chaco. Sendo assim, era importante que suas fundações fossem pensadas como instrumentos a favor da presença do Estado colonial em regiões estratégicas, que, consequentemente, implicariam conflitos armados. As próprias autoridades civis e religiosas incentivaram os grupos reduzidos a interferirem militarmente nas questões das fronteiras e na proteção das cidades.

Foi pensando assim, por exemplo, que foram canalizados esforços, na década de 1740, para a fundação de uma redução de índios Calchaqui próxima à cidade de Santa Fe, que estava sendo constantemente atacada pelos Abipone. Sendo assim, era imprescindível a cooperação dos futuros neófitos para a segurança da região, como

Anos 90, Porto Alegre, v. 22, n. 41, p. 267-298, jul. 2015 
Estar, e não ser, aliado: A sociabilidade dos índios do Chaco...

percebeu o Promotor Fiscal da Coroa: "Como más convenga digo que es constante y notoria la pretensión de dichos indios Calchaquís y su perseverancia en solicitud de su reducción a Nuestra Santa Fe Católica" (EXPEDIENTE CALCHAQUIS, [21/12/1740], p. 24).

Duas parcialidades do mesmo grupo étnico, divididas por um rio, poderiam manter guerras intermitentes que oportunizariam aos hispano-crioulos se aproveitarem desses conflitos como estratégia de defesa. Em julho de 1790, a expedição promovida pelo Coronel de Salta, Adrian Fernandez Cornejo, foi atacada por índios Mataguayo, que os esperavam em uma emboscada nas margens do rio Bermejo. No dia seguinte ao incidente, outro grupo desta mesma etnia veio ter com o Coronel, por meio de uma índia Toba casada com um cacique Mataguayo. Desarmados, os índios procuraram convencer os espanhóis de que não tiveram qualquer participação naquela emboscada y "[...] que habían tenido muy a mal las operaciones de los de su nación". O Coronel, acreditando na versão dos nativos, procurou selar uma aliança informal dando-lhes alguns objetos que trazia na expedição. Em troca, os índios levaram "carneros, conejos y carne de corzuela” num ato de retribuição (CORNEJO, 1790, p. 21-23).

Uma década antes, o militar Francisco Gavino Arias já havia identificado, em uma expedição realizada no mesmo rio, que os Mataguayo se diferenciavam em pelo menos dois grupos: os "Coronados", que, além do seu idioma nativo, falavam também o Guarani; e os "Churumatas", que "[...] entienden, a más de la nativa, diferentes lenguas por los varios cautivos que tienen entre ellos" (ARIAS, [1780], fl. 321v). Estas diferenças dentro de um mesmo grupo foram usadas na estratégia colonial, visando a empreender o domínio da região. As alianças firmadas entre alguns grupos indígenas e os brancos possibilitavam aos últimos a ampliação de suas defesas aos assaltos de outros indígenas. Assim, em 1725, um grupo armado de índios Guarani das missões dos rios Paraná e Uruguai foram encaminhados para ajudar na defesa da cidade de Santa Fe, que estava sob ataque dos Abipone e Mocovi (ANÔNIMO, [1735], fl. 5). A situação foi momentaneamente controlada, mas as invasões mantiveram-se, o que resultou na fundação de uma redução de índios Calchaqui próxima à cidade, em 1740, aos cuidados dos missionários franciscanos. A justificativa para o empreendimento foi bastante pontual: "[...]

Anos 90, Porto Alegre, v. 22, n. 41, p. 267-298, jul. 2015 
dichos indios sirven de ante mural y defensa a la referida ciudad de Santa Fe, contra los bárbaros, que con frecuentes hostilidades han muerto y cautivado antecedentemente mucha gente" (CONSELHO DAS ÍNDIAS, [12/08/1747], p. 2).

Ainda que os índios fossem, no entendimento dos espanhóis, inconstantes e violentos, o benefício que se poderia ter com a fundação de reduções em locais específicos para a segurança do território colonial era fundamental. Pretendia-se, com as missões do Chaco, interromper as hostilidades praticadas pelos índios por meio da sua pacificação e, assim, atrair um contingente indígena que auxiliasse a Coroa a defender seu território contra portugueses e índios não reduzidos que oferecessem perigo. Daí os projetos de fundação das reduções priorizarem locais estratégicos, posicionando-se como um "cordón fronterizo" (PAZ, 2007, p. 280), que intencionava barrar os avanços das hordas de índios não reduzidos hostis aos espanhóis, funcionando, consequentemente, como "enclaves defensivos antes que civilizatorios y religiosos” (LUCAIOLI, 2011, p. 102).

Porém, as relações mantidas entre os índios reduzidos e os selvagens também era uma realidade enfrentada pelas autoridades coloniais. Assim constatou o Bispo de Tucumã, em carta do Governador da Província escrita em novembro de 1764, que os Abipone reduzidos no rio Paraná, "[...] confederados con los indios salvajes, hacían correrías en nuestro territorio y hostilizaban nuestros pueblos [...]" - concluindo que estes eram "[...] reos de muerte, porque pasarse al enemigo quien es de nuestra parte me parece un crimen acreedor a pena capital" (AUTOS, [02/09/1775], fl. 2). Em outra oportunidade, o Bispo, em carta de 1768 ao Rei da Espanha, deixa clara sua preocupação em relação à segurança das cidades e fazendas da província. Em um posicionamento rigorosamente antijesuítico, citou alguns exemplos de grupos reduzidos que se voltaram contra os espanhóis ou mantiveram contato com índios selvagens, concluindo que muitas reduções são "[...] albergue de hombres salvajes, que salían de allí a robar y matar cuanto hallaban" (BRABO, 1872, p. 136-137). Criou-se uma situação delicada, em que as reduções eram importantes para a defesa do território e da pacificação dos nativos, mas não davam a garantia de uma colaboração irrestrita por parte dos índios. 
Estar, e não ser, aliado: A sociabilidade dos índios do Chaco...

De qualquer forma, os missionários e as autoridades civis tentaram tirar o máximo de proveito destas atuações bélicas, fazendo com que os índios direcionassem-nas aos interesses da Coroa, como foi o caso dos índios Zamuco, reduzidos em San Ignácio, no atual Chaco boliviano. O padre Agustín Castañares, fundador daquela redução na década de 1720, intentando reduzir os índios Terena - e, com isso, abrir um caminho que ligasse o rio Paraguai e o alto Peru pelo rio Pilcomayo (CA, 1730-1735, p. 193) - levou os neófitos Zamuco para auxiliá-lo no convencimento dos índios. Porém, no caminho, o grupo deparou-se com índios Caypotarade, uma parcialidade Zamuco, que, além de negar a redução, ataca-os, matando o cacique Luis Gozocoerade. Os Zamuco, enfurecidos, confrontaram os inimigos a fim de vingar o seu cacique: "Quería poner fin el Padre misionero a esta sangrienta batalla, pero al llegar él al campo encontró a los suyos tan fuera de sí, que le era completamente imposible conseguir, que se moderasen estos neófitos recién convertidos" (CA, 1735-1743, p. 499-500).

A situação saiu do controle porque os índios reduzidos não partiram da lógica que as autoridades coloniais tentaram impor em relação a estas investidas militares: só seriam permitidas guerras defensivas ou que tivessem como pretexto atuações favoráveis à empresa missionária. ${ }^{2}$ Não estavam, então, permitidas incursões beligerantes sem a aprovação das autoridades, muito menos aquelas que cumprissem interesses dos indígenas, como as vinganças. Para os índios, esta divisão entre uma guerra permitida e uma guerra condenável pode não ter feito muito sentido, ainda mais porque, ao serem admitidos pela empresa reducional, deveriam também cumprir funções militares - recebendo, inclusive, suporte bélico autorizado pela realeza:

[...] atendiendo a lo referido me dé por bien servida de dichos indios y sus doctrineros así en haber tenido los dichos arcabuces, como en el modo con que han usado de ellos y los dejan ahora y mande poner presidio de españoles en la frontera por cuya cuenta corra la defensa y seguridad de esa Provincia y señale a los dichos indios un Protector desinteresado cristiano y celoso del servicio de Dios y bien 
universal, y habiéndose visto en el Consejo Real de las indias con los demás papeles tocantes a esta materia y lo que sobre todo dijo y pidió el Fiscal en el (ORLEANS, [30/04/1668], fl. 138-138v).

Nesta Cédula Real, emitida pela Rainha Consorte da Espanha, oficializa-se a permissão para o uso de armas de fogo nas reduções submetidas aos cuidados da Companhia de Jesus. Já desde a primeira metade do século XVII, os padres da Ordem Inaciana, principalmente por meio de Ruiz de Montoya, solicitavam a permissão Real para o abastecimento e uso de armas nas reduções, como forma de proteção aos ataques de índios não reduzidos e dos bandeirantes portugueses (QUARLERI, 2009). O que levou a Rainha a permitir a introdução dos instrumentos bélicos foram os argumentos usados pelo padre Pedro Bermudo, Procurador Geral da Companhia de Jesus, que giraram em torno dos exemplos benéficos do uso de milícias indígenas para a defesa das fronteiras coloniais. Com isso, autorizava-se a formação de grupos militares oriundos das missões fundadas e cuidadas pelos jesuítas, armando-se os índios para eventuais convocações militares. Para o contexto chaquenho, a decisão foi uma vitória para os missionários que atuariam junto aos índios da região.

Apesar de a empresa reducional no Chaco ter se iniciado somente algumas décadas depois da promulgação da Cédula supracitada, o uso de armas de fogo pelos chaquenhos reduzidos foi um importante expediente empregado naquelas missões, principalmente no Chaco meridional, limitado pelo rio Salado, por onde os índios pampianos faziam seus ataques. Na virada para o século XVIII, quando as missões jesuíticas no Chaco passaram a ter um caráter sedentário em detrimento das visitas itinerantes realizadas até então, formar um corpo de defesa armado e instruído - para, além do combate a invasores, a promoção de investidas de cooptação de aliados indígenas - foi um dos principais tópicos da agenda das autoridades coloniais. Aqueles grupos indígenas que eram hostis e violentos em relação à presença colonial foram os principais alvos na tentativa de uma conciliação de paz, sobretudo por causa de suas habilidades de guerreiros. O padre José Jolís informa que, a 
Estar, e não ser, aliado: A sociabilidade dos índios do Chaco...

partir de 1748, os Abipone, já em "comunicación y amistad” com os espanhóis, "[...] se apoderaron y todavía están provistos de gran cantidad de caballos, sables, lanzas y espadas [...]", superando os europeus na guerra a cavalo e já bastante habilidosos no manejo de armas de ferro (1789, p. 288-289). O mesmo havia afirmado o Bispo de Tucumã, em 1768, sobre o perigo de manter os índios armados, afirmando que "[...] mientras no se les desarme y se les deje a pié, siempre hemos de vivir sobresaltados [...]", concluindo que estavam "más bien armados que nuestros españoles" (BRABO, 1872, p. 139-140).

E foi justamente esta rápida aptidão adquirida pelos nativos que deixou os espanhóis receosos. Ao mesmo tempo em que era importante manter os índios das reduções aptos para os confrontos, a imagem que se estabeleceu sobre suas atitudes por meio da ideia da inconstância preocupava as autoridades: armar e preparar os índios para a guerra, tendo em consideração suas ações muitas vezes inesperadas, podia ser muito perigoso e contrariar os objetivos iniciais. Por isso, durante os acordos de paz e redução de parcialidades Mocovi e Toba, na década de 1770, o Governador da Província de Tucumã, Gerónimo Matorras, estabelece onze pontos a serem cumpridos pelos índios - representados pelo cacique Mocovi Paikín. Contemplaram-se preocupações variadas a respeito desta aliança, desde a responsabilidade em manter o acordo sem agressões, até a prestação de auxílios para busca de novos aliados (para uma análise do acordo estabelecido entre os espanhóis e o cacique Paikín, cf. NESIS, 2008). No último tópico, fica evidente a preocupação em relação a armar os futuros neófitos:

Que sin embargo de habérseles negado por el Señor Gobernador armas de pistolas, lanzas y machetes, que le habian pedido para defenderse de sus enemigos, quedaban ciertos de la promesa que les había hecho de atender a su pretensión cuando hubiesen dado pruebas de su fiel vasallaje al Rey de España, con la buena amistad y buena correspondencia que profesarían con todos los españoles (BRIZUELA, 1774, p. 23, grifos nossos). 
Para o Governador, era imprescindível que os índios provassem a sua disposição em firmarem alianças com os espanhóis, pois sem ela a relação se tornaria fraca e a distribuição de armas seria suspensa. Porém, no próprio trecho, fica evidente pelo menos uma das intenções que levou este grupo a acordar paz com os espanhóis: a procura por novas alianças para suas antigas guerras. Ao que parece, Paikín e seus seguidores estavam investindo na atualização de suas redes de aliança e, com isso, os espanhóis eram integrados como parte da mecânica bélica.

Na mesma lógica, os Payaguá, vendo-se em território marcado pela presença dos espanhóis no Paraguai e pelos portugueses de Cuiabá, "[...] reflexionando que no había para ella ningún medio de escaparse [...]", resolveram "[...] hacer la paz de buena fe con los españoles, aliándose a ellos del modo más estrecho". Sem comprometerem-se de fato com alguém, os Payaguá faziam "una alianza ofensiva y defensiva contra todo el mundo, sin excepción” (AZARA, 1809, p. 65).

Para os índios, integrar-se ao projeto missionário não significava aderir à causa espanhola - o que foi uma das maiores decepções das autoridades coloniais. Os inimigos dos espanhóis não seriam automaticamente seus inimigos - e o mesmo ocorria com as alianças. A lógica de alianças e inimizades, para os chaquenhos, não se alterava em função do evento reducional. Isto acabava reforçando a imagem de índios " [...] incapaces de admitir y mantener verdaderas paces, aunque en ellas se les proporcionen conveniencias ventajosas, a las que desfrutan de sus tiranas hostilidades" (CABILDO DE ASSUNÇÃO, [30/05/1763], fl. 2v-3). Os índios aceitavam tratar com os espanhóis buscando, obviamente, vantagens para si que, muitas vezes, giravam em torno do seu interesse em manter vivas as guerras com outros grupos indígenas.

Assim, os objetivos destes acordos de aproximação entre os colonos e os nativos divergiam de tal forma que, aos índios, era interessante criar essas alianças com os espanhóis buscando novas formas de enriquecer materialmente seus conflitos. E não só as alianças em si, mas também as armas providenciadas para as reduções jesuíticas somaram uma importante vantagem à dinâmica da guerra indígena. Florián Paucke, a fim de rebater as críticas sobre o perigo 
Estar, e não ser, aliado: A sociabilidade dos índios do Chaco...

de as armas existentes nas reduções serem roubadas, assume que os povoados administrados pelos padres da Companhia de Jesus estavam bem supridos de armamentos: "[...] en cada pueblo que han establecido cerca de las fronteras portuguesas, han guardado en una cámara algunas armas de fuego y esto tan luego por orden del Rey de España como también [era la orden] que se los capacitara de tratar [manejar] el arma de fuego para que pudieren defenderse" $(1767$, t. 2, p. 291, grifos do autor).

Além de terem sido armados pelos próprios missionários - sob aval do Rei -, treinados e capacitados para fazer guerra em nome da Coroa espanhola e terem ficado perigosamente próximos de grupos indígenas hostis aos espanhóis, os índios que viviam nos povoados missionários tiveram também a seu favor a organização do espaço reducional, que lhes proporcionava um ambiente favorável ao estabelecimento de alianças fraternais entre grupos que, na forma tradicional, viveriam distantes. Assim, os jesuítas, por meio da reorientação e administração das festas e da guerra, conseguiam "[...] mantener grandes concentraciones poblacionales sin destruir la autonomía relativa de las unidades políticas previas que constituía la base de su funcionamiento económico" (WILDE, 2009, p. 79). Os índios aderiam à rotina reducional, mas utilizavam-na a favor de seus interesses sociológicos - o que, na prática, resultava em uma disciplina não muito rigorosa em relação à agenda catequética e implicava fugas e longas ausências do espaço reducional. As reduções foram uma alternativa para a sociabilidade de muitos grupos chaquenhos, sendo a comunhão cristã interpretada e inserida na sua dinâmica relacional de tal forma que possibilitava a geração de alianças para guerra dentro dos povoados. Florián Paucke descreve o momento que os Mocovi, sob sua tutela na redução de San Javier, preparavam-se para se defender de um ataque de índios não reduzidos que, após sofrerem baixas num conflito anterior, estavam dirigindo-se para o povoado missioneiro buscando vingança: "Ya todos habían vestido sus corazas de cuero de buey y estaban [pintados] en la cara y por todo el cuerpo como vivos fantasmas diabólicos”. O jesuíta também ressalta "[...] la ferocidad de los indios en armas, el sonido de las cornetas, trompas indias y de otros diversos pífanos, el griterío desaforado" (1767, t. 2, p. 301, grifos do autor).

Anos 90, Porto Alegre, v. 22, n. 41, p. 267-298, jul. 2015 
Mesmo inseridos num lugar/situação em que eram instruídos constantemente nos ensinamentos cristãos em detrimento de seus costumes e de suas práticas autóctones, mantinham os rituais que prenunciavam o seu modo de fazer a guerra - que, por sinal, era incentivada pelos próprios missionários e pelas autoridades hispânicas na medida em que os índios aliados formavam um importante corpo defensivo colonial. Os preparativos que antes eram realizados dentro da aldeia foram transportados para as reduções; a "vocinglería de sus caracoles y flautas" (SOTOMAYOR, [c. 1711], fl. 1), que antes ressoava de dentro da mata fechada, sem se saber ao certo de onde se originavam, agora faziam vibrar as construções de pedra de suas novas casas.

\section{Considerações finais: uma análise do conflito entre os Mocovi e os Abipone}

A união que se estabelecia entre os índios de uma mesma redução foi, até certo ponto, um fator favorável para os missionários. Se a defesa das reduções e, até mesmo, de toda uma região estava assegurada pela formação de milícias indígenas, era por causa delas que a situação podia sair do controle. Os Mocovi foram os causadores, ao lado dos Abipone, de uma grande dor de cabeça para as autoridades coloniais. Estes dois grupos, apesar de terem sido responsáveis pela fundação de pelo menos onze reduções, provocaram situações constrangedoras e até violentas, que obrigaram a intervenção dos Governadores para se tentar estabelecer acordos.

A primeira redução prioritariamente de índios Mocovi foi San Javier, fundada em 1743, à margem do rio Paraná, em um ponto estratégico para a defesa da fronteira santafesina contra os índios pampianos. Segundo o padre Pedro Lozano, após alguns contatos com o colégio jesuítico da cidade de Santa Fe, os índios "[...] declararon abiertamente que querían hacerse cristianos, con tal que tuviesen por misioneros a Padres de la Compañía" (CA, 1735-1743, p. 575). A redução é erguida e os esforços para sua manutenção estão retratados no pedido que o Governador do rio da Prata fez ao Rei para que as cidades daquela Província fornecessem "una voluntaria 
Estar, e não ser, aliado: A sociabilidade dos índios do Chaco...

limosna", cuja ajuda "[...] ha de ser suficiente para la prosecución y existencia del referido pueblo, sin el menor cuesto al Real Erario de Vuestra Majestad" (ROZAS, [20/12/1743], fl. 2). Não demorou muito para que a redução já mostrasse efeitos benéficos à defesa da região: Paucke relatou o violento confronto ocorrido entre os Mocovi de San Javier, em uma rara aliança com os Abipone de San Jerónimo, contra índios não reduzidos que, alguns dias antes, haviam atacado o missionário e seus índios, ferindo a mão do padre. A batalha foi vencida pelos índios reduzidos, que somaram mais de setenta inimigos mortos, além de voltarem "[...] de la batalla con cuatro cabezas enemigas cortadas que eran las cabezas de los caciques salvajes más principales que se habían mostrado los más valientes en el combate" (PAUCKE, 1767, t. 2, p. 311-312). Os vitoriosos também fizeram colares com orelhas e narizes decepados dos inimigos mortos para adornar seus cavalos e apresaram "cuarenta y seis niños cautivos de ambos sexos". No final do relato, Paucke, em tom crítico, escreveu que os Abipone de San Jerónimo “[...] se habían dedicado más bien a saquear que a pelear [...]", além de terem apresado trinta crianças, já que "[...] tenían entre los salvajes, que también se llamaban Abipones, muchos parientes consanguíneos" (PAUCKE, 1767, t. 2, p. 311-312).

Os atos cometidos pelos índios após a batalha - que nos permitem imaginar um ambiente reducional com cabeças fincadas em lanças e colares de narizes e orelhas distribuídos em vários cavalos - parecem não ter despertado tanto interesse no autor do relato, que prefere ressaltar o fato de os inimigos serem da mesma etnia que os moradores de San Jerónimo - situação que não era novidade: no mesmo livro, o ex-missionário narra o confronto entre dezoito índios não reduzidos e um pequeno grupo de Mocovi que estavam cuidando de alguns gados próximos à redução. $\mathrm{O}$ conflito iniciou-se quando um dos Mocovi, que atuava como capataz, avistou os inimigos e partiu em sua direção, desferindo flechas e matando alguns deles. Ao final, o grupo acabou por matar o índio e retirou-se em fuga. Seus filhos, que presenciaram o confronto e a morte do pai, passaram a "[...] alistar gente de pelea para buscar los asesinos [...]", que acreditavam ser os Abipone. Porém, logo todos ficaram sabendo que o grupo invasor era Mocovi, guiado por um cacique 
chamado "El indio crespo", famoso entre os espanhóis e que, daquela redução, "[...] había ya muchos de sus amigos cuyos caballos él no había respetado" (PAUCKE, 1767, t. 2, p. 34-37).

O conflito entre parcialidades de uma mesma etnia conotava uma complexa relação que permeava os grupos chaquenhos, e as autoridades coloniais tiveram que saber lidar com o fato de, por vezes, essas parcialidades se digladiarem e, por outras, se ajudarem. O cacique abipone Miguel Benavides, da redução de San Jerónimo, denunciou, através de uma carta escrita em espanhol, os inúmeros ataques cometidos pelos Mocovi das reduções de San Javier e San Pedro que, "[...] convocados con las naciones bárbaras, nombradas Tobas, Vilelas, Chunupis, Lenguas y Mocobies", hostilizavam o povoado e sua fazenda, afirmando que dessa forma poderiam "[...] culpar a los infieles y descargase ellos de sus atentados" (BENAVIDES, [c. 1780], fl. 2 e 10). Assim, além da incerteza a respeito do tipo de relação que as parcialidades mantinham entre si, havia ainda o conflito entre os Abipone reduzidos em San Jerónimo e os Mocovi de San Javier e San Pedro, que passou a ser destacado pela documentação após a expulsão dos jesuítas. Atuando a partir de suas reduções, esses dois grupos provocaram uma série de confrontações que iam desde furtos às fazendas até ataques violentos aos moradores dos povoados missionários. A interferência do Estado colonial fez-se na tentativa de selar um acordo de paz entre os grupos envolvidos em 29 de março de 1772 (BRUNO, 1970, p. 223). Porém, o acordo mostrou-se inútil e as hostilidades continuaram. Em uma carta escrita na cidade de Santa Fe para o Governador do Rio da Prata, alerta-se quanto à intenção dos índios das reduções de San Pedro e San Javier, junto com índios Toba, Vilela e Mocovi não reduzidos, de atacar e destruir San Jerónimo (eod. loc.). A resposta Abipone não demorou: em 1776, os índios de San Jerónimo, liderados por Benavides, atacaram a redução de San Pedro e roubaram todos os seus cavalos (id. ibid., p. 225).

Frente a estes impasses, o Governador Juan José de Vértiz mandou o Tenente de Santa Fe reunir os caciques e os corregedores das três reduções a fim de "[...] establecieren una paz firme". Na presença do Bispo Sebastián Malvar y Pinto, do Administrador dos povoados José Tarragona, do Capitão Francisco Solano e dos 
Estar, e não ser, aliado: A sociabilidade dos índios do Chaco...

missionários responsáveis por San Jerónimo e San Javier, os índios concordaram com os treze tópicos que compunham a nova tentativa de uma paz entre as reduções. Os itens do acordo giravam em torno do perdão mútuo pelos agravos cometidos, sem que pudessem vir a alegar direitos sobre bens roubados até então. Mandava a redução de San Jerónimo devolver "[...] los dos niños cautivos que tiene del pueblo de San Pedro", e que todos os três povoados convencessem os seus aliados não reduzidos a se reduzirem "[...] y que de no conseguirlo, no los trataran como a deudos, sino como a enemigos de la religión cristiana y no los consentirán en su pueblo, ni las darán ayuda alguna, auxilio, ni favor". Também ressaltava a importância das práticas litúrgicas para o bom funcionamento das reduções, pontuando que a hierarquia de obediência deveria ser respeitada. $\mathrm{O}$ último item mandava os corregedores proibirem os índios de pintarem seus corpos, "[...] y que conforme puedan se vayan vistiendo como los españoles, para que la mudanza del traje quite de algún modo las especies antiguas del gentilismo" (ECHAGÜE; ANDIA, [19/06/1779]; cf. BRUNO, 1970, p. 226-227).

Além de tentar solucionar o vergonhoso conflito armado que existia entre as reduções, o acordo buscava diminuir o contato com os selvagens e, daí, melhorar os hábitos indígenas. Para as autoridades, havia uma relação direta entre a dificuldade em converter os índios - e civilizar seus costumes - e o contato que eles mantinham com os grupos não reduzidos. Esta lógica já era acionada pelos missionários desde os primeiros contatos com os nativos, dando razão ao argumento, segundo o qual, por meio das reduções, os índios estariam livres dos maus exemplos que os colonos poderiam passar-lhes. Partia-se, assim, da ideia de que os índios não tinham uma cultura - e, muito menos, uma cosmologia que a estruturasse -, mas sim hábitos viciados, tão mutáveis quanto uma troca de roupas.

Porém, a situação mostrava-se mais complexa: o tratado de 1779 também não surtiu os efeitos pretendidos e os índios continuaram se hostilizando. No final do ano seguinte, o missionário responsável por San Pedro informa, em carta enviada ao explorador Francisco Gavino Arias, que já não conseguia mais conter os seus índios na redução, “[...] no porque aquellos Mocobies sean inconstantes en su religión, sino porque los Abipones los hostilizan de tal modo que no hay luna en 
que no los asalten [...]", provocando mortes, apresamentos de cativos e roubando os recursos de suas estâncias (ARIAS, [1780], fl. 278).

Mesmo reduzidos, os índios não mudaram a sua lógica social, nem o seu entendimento sobre as relações de guerra ou trocas. Mantiveram-se constantes em sua inconstância, produzindo as alianças e as inimizades ao sabor de sua sociologia: reduzidos ou não, aliados de outros grupos nativos ou com espanhóis ou portugueses, os índios mostraram-se mais interessados na manutenção das relações em si do que como elas se formulavam - daí a quase negligência que os chaquenhos demonstravam em relação aos acordos de paz ou não agressão que as autoridades coloniais se esforçavam em, burocraticamente, implantar. A consequência disso era um aparente descaso dos índios em relação a tudo e a todos, como se fossem impenetráveis ao diálogo e aos acordos oficiais - salvo raríssimas exceções, diriam os colonos.

\section{TO STAY, AND NOT TO BE, ALLIED: THE CHACO'S INDIANS SOCIABILITY DURING THE COLONIAL ADVANCE IN THE 18TH CENTURY}

Abstract: When missionaries and government officials were instructed by the Spanish Crown to explore and colonize the Chaco Region to establish a direct route between the port of Buenos Aires and the Andean mines, the contact made with natives was, according to what can be evidenced in the documentation produced, the greatest difficulty faced by the Spanish people who tried to settle in the region. One of the main complaints of missionaries and settlers revolved around the native lack of commitment regarding contracts or alliances, for example, for the establishment of catechetical reductions. The Indian cooperation, at first, soon turned into betrayal in the Spaniards eyes, when native people abandoned reductions or involved in illicit trades with the Portuguese people. This way of proceeding was identified by the settlers, who tried many ways to reverse it, as an inconstant behavior and as a misconduct. This article tries to demonstrate that such inconstancy actually was a fundamental aspect of the native sociological system, in which alliances or enmities were the way to boost the sociability of Chaco groups and, thus, maintain its integrity.

Keywords: Indians of Chaco. Indigenous inconstancy. Alliances and enmities. Eighteenth Century. 
Estar, e não ser, aliado: A sociabilidade dos índios do Chaco...

\section{Notas}

${ }^{1}$ A comparação da inconstância indígena com a instabilidade do mercúrio já havia sido feita, décadas antes, pelo padre Pedro Lozano: "Pero precisamente esta costumbre de salir de su pueblo, los malos ejemplos, la flojedad, el embrutecimiento y no sé qué oculto influjo siniestro, los volvió inquietos como el mercurio, así, viendo ellos andar a sus parientes, luego se echaban ellos a andar también, sin saber a dónde" (CA, 1735-1743, p. 406).

${ }^{2}$ Uma situação parecida ocorreu no conflito entre os Payaguá e os índios da redução de Yapeyú, povoado jesuítico situado no rio Uruguai, responsável pela fronteira com a região pampiana e formado por "parcelas consideráveis de Charruas, Yarós e alguns Guenoas" (SANTOS; BAPTISTA, 2007, p. 243-244). Após serem atacados pelo grupo chaquenho, os índios da redução foram ordenados a "atacar enérgicamente a estos bárbaros, capturarlos y llevarlos a su reducción, tratándolos allí benignamente, en cuanto fuese posible". Porém, "no obedecieron a esta última advertencia los de Yapeyú, y mataron a muchos de ellos, o hicieron matarlos por los charrúas" não reduzidos (CA, 1735-1743, p. 410).

\section{Referências}

AGI - Archivo General de Indias (Sevilha)

AGN - Archivo General de la Nación (Buenos Aires)

AHN - Archivo Histórico Nacional (Madri)

AMN - Archivo del Museo Naval (Madri)

BME - Biblioteca del Museo Etnográfico (Buenos Aires)

BNE - Biblioteca Nacional de España (Madri)

RAH - Biblioteca de la Real Academia de la Historia (Madri)

ANDREU, Pedro Juan, S.J. [22/11/1757] Carta del padre Pedro Juan, jesuita, al Procurador General Simón Bailina, con la relación de la vida del P. Francisco Ugalde, muerto por los indios Mataguaios del Paraguay. Miraflores, 22 de novembro de 1757. BNE, microfilme 5940.

ANÔNIMO [1735] Relación compendiosa de los servicios que han hecho a su Majestad los Indios de las doctrinas que están a cargo de los padres de la Compañía de Jesús en esta Provincia del Paraguay de Nación Guaranís, o como los llaman vulgarmente tapes, desde el año 1637 hasta octubre del presente 1735,

Anos 90, Porto Alegre, v. 22, n. 41, p. 267-298, jul. 2015 


\section{Guilherme Galhegos Felippe}

así en el distrito del gobierno de Buenos Aires, como en el del Paraguay. AGN IX 6-9-7.

ARCE, José Francisco de, S.J. [23/07/1707] Declaração sobre os índios das missões dos rios Paraná e Uruguai mediante o questionário proposto pelo padre Bartolomé Jiménez. San Miguel, 23 de julho de 1707. AGN IX 6-9-5.

ARIAS, Francisco Gavino. Diario y descripción de la expedición del año 1780 a cargo de D. Francisco Gavino Arias, en consorcio de D. Lorenzo Suárez de Cantillana, para la erección de dos reducciones en el centro del Gran Chaco Gualamba con una general noción y descripción geográfica de todo el Chaco, su extensión, cualidades e indios que lo habitan. RAH, Mata Linares 9-1661 [1780]. AUTOS. Autos para aprovação de entrada ao Chaco. Salta, 02 de setembro de 1775. AGI. Buenos Aires 49, 02 set. 1775.

AZARA, Félix de. Geografía física y esférica de las Provincias del Paraguay y Misiones Guaranies, Montevideo: Anales del Museo Nacional de Montevideo (Sección Histórico-Filosófica, Tomo I) 1790 [1904].

. Viajes por la América Meridional. Tomo II. Buenos Aires: El Elefante Blanco, 1809 [1998].

BENAVIDES, Miguel Jerónimo. Carta do Cacique ao Vice-rei do Rio da Prata, Don Juan José de Vértizy Salcedo. San Jerónimo. AGN IX 4-1-6, [c. 1780]

BISPO DE CÓRDOBA. El Obispo de Tucumán da cuenta a Vuestra Majestad de su visita general y del estado de la Provincia. Córdoba, 20 de abril de 1729. AGI, Charcas 347.

BRABO, Francisco Javier (Org.). Colección de Documentos Relativos a la Expulsión de los Jesuitas de la República Argentina y del Paraguay, en el Reinado de Carlos III. Madri: Establecimiento tipográfico de José María Perez, 1872.

BRIZUELA, Blas Joaquim de. "Diario de la expedición hecha en 1774 a los países del Gran Chaco desde el Fuerte del Valle, por D. Geronimo Matorras". In: ANGELIS, Pedro de. Colección de Obras y Documentos Relativos a la Historia Antigua y Moderna de las Provincias del Río de la Plata. Buenos Aires: Imprenta del Estado, t. 6, 1837. 1774 [1837].

BRUNO, Cayetano. Historia de la Iglesia en la Argentina, tomo 4. Buenos Aires: Editorial Don Bosco, 1968.

Historia de la Iglesia en la Argentina, tomo 6. Buenos Aires: Editorial Don Bosco, 1970.

BUENO, Cosme. Descripción del Gran Chaco por D. Cosme Bueno. AMN, caja 0114, ms. 123, doc. 1 [1775].

Anos 90, Porto Alegre, v. 22, n. 41, p. 267-298, jul. 2015 
Estar, e não ser, aliado: A sociabilidade dos índios do Chaco...

CA, 1730-1735. Cartas anuas de la Provincia del Paraguay, año 1730-1735. São Leopoldo: Instituto Anchietano de Pesquisa/UNISINOS, 1994 (transcrição de Carlos Leonhradt, S.J. 1928) [mimeo].

1735-1743. Cartas anuas de la Provincia del Paraguay, año 1735-1743. São Leopoldo: Instituto Anchietano de Pesquisa/UNISINOS, 1994 (transcrição de Carlos Leonhradt, S.J. 1928) [mimeo].

1750-1756. Cartas anuas de la Provincia del Paraguay, año 1750-1756. São Leopoldo: Instituto Anchietano de Pesquisa/UNISINOS, 1994 (transcrição de Carlos Leonhradt, S.J. 1928) [mimeo].

CABILDO DE ASSUNÇÃO. Carta ao Rei da Espanha. Assunção, 30 de maio de 1763. AGI, Buenos Aires 48.

CLASTRES, Pierre. A Arqueologia da Violência. São Paulo: Cosac Naify, 1980 [2004].

CONDE DE SUPERUNDA. Relação sobre as missões que estão a cargo da Companbia de Jesus nas provincias de Buenos Aires, Paraguai e Tucumã feita pelo Conde de Superunda ao Rei da Espanha. Lima, 15 de fevereiro de 1751. BME, Carpeta J (J.10).

CONSELHO DE ÍNDIAS. Carta ao Rei da Espanha. Madri, 12 de agosto de 1747. BME, Carpeta J (J.3).

CORNEJO, Adrian Fernandez. "Expedición al Chaco por el Río Bermejo. In: ANGELIS, Pedro de. Colección de Obras y Documentos Relativos a la Historia Antigua y Moderna de las Provincias del Río de la Plata. Buenos Aires: Imprenta del Estado, t. 4, 1790 [1836].

DOBRIZHOFFER, Martín, S.J. Historia de los Abipones. Resistencia: Universidad Nacional del Nordeste, 3 tomos, 1784 [1967-1970].

ECHAGÜE Y ANDIA, Melchor de. Disposições feitas pelo Tenente Governador de Santa Fe, após resolução dos conflitos entre Mocobi e Abipone reduzidos. Santa Fe, 19 de junho de 1779. AGN IX 4-1-6, [19/06/1779].

EXPEDIENTE CALCHAQUIS. Expediente sobre nova redução de Calchaquis em Santa Fé. Iniciado em 21 de dezembro de 1740. BME, Carpeta I (I.12).

FERNÁNDEZ, Manuel Ignacio. Carta do Intendente de Buenos Aires ao Ministro de Indias, Don José de Gálvez. Buenos Aires, 08 de junho de 1779. AGI, Buenos Aires 49.

FERNÁNDEZ, Patricio. Relación historial de las misiones de indios chiquitos que en el Paraguay tienen los padres de la compañia de Jesús. Madrid: Librería de Voctoriano Suárez, 2 volumes 1726 [1895].

Anos 90, Porto Alegre, v. 22, n. 41, p. 267-298, jul. 2015 


\section{Guilherme Galhegos Felippe}

FURLONG, Guillermo. Entre los Vilelas de Salta. Buenos Aires: Academia Literaria del Plata, 1939.

JOLÍS, José, S.J. Ensayo sobre la Historia Natural del Gran Chaco. Resistencia: UNNE/ Facultad de Humanidades-Instituto de Historia, 1789 [1972].

LOZANO, Pedro, S.J. Descripción chorographica de Terreno Ríos, Arboles, y Animales de los dilatadísimas provincias del Gran Chaco, Gualamba, y de los Ritos y Costumbres de la innumerables naciones de barbaros e infieles que le habitan. Córdoba: Colegio de Asunción, 1733.

LUCAIOLI, Carina. Abipones en las fronteras del Chaco. Una etnografía histórica sobre el siglo XVIII. Buenos Aires: Sociedad Argentina de Antropologia, 2011.

MONTENEGRO, Juan de, S.J. Breve noticia de las misiones, peregrinaciones apostólicas, trabajos, sudor y sangre vertida en obsequio de la Fe del venerable padre Augustin Castañares de la Compañia de Jesís. Buenos Aires, 15 de agosto de 1745. AHN, Diversos-colecciones 28, doc. 11.

MONTEROS, Juan Alonso Espinosa de los. Bando de convocação do Governador de Tucumã para guerra aos indios do Chaco. Salta, 24 de abril de 1745. AGI, Charcas 284.

NESIS, Florencia. El Camino de Paikín: un acercamiento a los grupos mocoví del Chaco a través del tratado de 1774. Avá. Revista de Antropología. Misiones, n. 13, 2008.

NUSDORFFER, Bernardo. Carta do Provincial da Companbia de Jesus do Paraguai ao Rei da Espanha. Buenos Aires, 30 de agosto de 1745. BME, Carpeta I (I.28).

ORLEANS, María Luisa de. Cédula Real ao Provincial da Companbia de Jesus da Provincia do Paraguai. Madri, 30 de abril de 1668. RAH, Mata Linares 9-1755,

PAUCKE, Florián, S.J. Hacia Allá y Para Acá. Una estadía entre los indios mocobies, 1749-1767. Tucumã: Universidad Nacional de Tucumán, 3 tomos, 1767 [19421944].

PAZ, Carlos D. “Pues nosotros somos capaces...'. Reclamos indígenas en las fronteras abipón - santafesinas. Segunda mitad del siglo XVIII". Anuario IEHS. Buenos Aires, n. 22, p. 273-298, 2007.

PETRAGRASSA, Angelo, S.J. Declaração sobre os indios das missões dos rios Paraná e Uruguai mediante o questionário proposto pelo padre Bartolomé Jiménez. San Tomé, 22 de julho de 1707. AGN IX 6-9-5.

QUARLERI, Lía. Rebelión y Guerra en las Fronteras del Prata: Guaraníes, jesuítas e imperios coloniales. Buenos Aires: Fondo de Cultura Económica, 2009.

Anos 90, Porto Alegre, v. 22, n. 41, p. 267-298, jul. 2015 
Estar, e não ser, aliado: A sociabilidade dos índios do Chaco...

ROZAS, Domingo Ortiz de. Carta do Governador do Rio da Prata ao Rei da Espanha. Buenos Aires, 20 de dezembro de 1743. AGI, Charcas 215.

Carta do Governador do Rio da Prata ao Rei da Espanha. Buenos Aires, 29 de outubro de 1744. AGI, Charcas 215.

SALCEDO, Miguel de. Carta do Governador do Rio da Prata ao Secretário de Estado

D da Espanha, Don José Patiño Rosales. Buenos Aires, 20 de julho de 1734. Buenos Aires: AGI, 523.

SÁNCHEZ LABRADOR, José. El Paraguay Católico. Buenos Aires: Imprenta de Coni Hermanos, 2 tomos, 1770 [1910].

SANTOS, Maria Cristina dos; BAPTISTA, Jean. "Reduções jesuíticas e povoados de índios: controvérsias sobre a população indígena (séc. XVII-XVIII)". História Unisinos, v.11, n. 2, p. 240-251, 2007.

SOTOMAYOR, Francisco Pimentel y. Copia del capitulo $1^{\circ}$ de la carta escrita por Don Francisco Pimentely Sotomayor, presidente de la Audiencia de Charcas, tocante a la guerra de los indios Mocovies en la Provincia del Tucumán. AGI, Charcas 284, [c. 1711].

VITAR, Beatriz. Guerra y misiones en la frontera chaqueña del Tucumán (1700-1767). Madrid: Consejo Superior Investigación Científicas, 1997.

. El impacto de la expulsión de los jesuitas en la dinámica fronteriza del Tucumán. In. ANDRÉS-GALLEGO, José (Coord.). Nuevas Aportaciones a la Historia Jurídica de Iberoamérica. Madri: Fundación Histórica Tavera, v. I, p. 1-118, 2000. Disponível em: <http://www.larramendi.es/i18n/consulta/registro.cmd?id=1217>. Acesso em: 20 fev. 2012.

VIVEIROS DE CASTRO, Eduardo. 2002. A Inconstância da Alma Selvagem. São Paulo: Cosac Naify, 2002.

WILDE, Guillermo. Religión y poder en las misiones de guaranies. Buenos Aires: SB, 2009.

Recebido em: 15/10/2013

Aprovado em: 19/02/2014

Anos 90, Porto Alegre, v. 22, n. 41, p. 267-298, jul. 2015 